\title{
FUZZY CONTROL CHART FOR MONITORING MEAN AND RANGE OF UNIVARIATE PROCESSES
}

\author{
Amanda dos Santos Mendes ${ }^{1 *}$, \\ Marcela A. G. Machado ${ }^{1}$ and Paloma M. S. Rocha Rizol ${ }^{2}$ \\ Received June 11, 2018 / Accepted May 14, 2019
}

\begin{abstract}
The control chart introduced by Shewhart is one of the most important quality control techniques used to detect special causes. Real world data are complicated to interpret since they involve a certain level of uncertainty that may be linked to human subjectivity or measurement device limitations. Fuzzy set theory can deal with such uncertainty and can be applied to traditional control charts. In this work, the values of the quality characteristic are fuzzified by the insertion of uncertainties and transformed into representative values for a better comparison with traditional control charts. The performance of a control chart can be measured by the average run length (ARL) and the extra quadratic loss (EQL). We observed in the present work that the fuzzy control chart has greater efficiency than the traditional control charts. An illustrative example demonstrates the application of the fuzzy control chart for the measurement of the volume contained in milk bags.
\end{abstract}

Keywords: control chart, fuzzy, average run length (ARL), extra quadratic loss (EQL).

\section{INTRODUCTION}

Control charts are used to monitor processes whose quality characteristic of interest is measurable. It consists of three lines, called upper control limit (UCL), central limit (CL) and lower control limit (LCL). When one or more sample points are outside the control limits, the chart indicates the presence of a change in the process and the user should look for the cause of the sign (Masood \& Shyen, 2016).

In addition to being able to monitor variables and attributes, control charts can be univariate when they study only one process quality characteristic or multivariate when monitoring two or

*Corresponding author - https://orcid.org/0000-0002-8995-2977

${ }^{1}$ Universidade Estadual Paulista "Júlio Mesquita Filho", Faculdade de Engenharia de Guaratinguetá, Departamento de Engenharia de Produção, Guaratinguetá-SP, Brazil. E-mail: prof.amandasmendes@gmail.com

2Universidade Estadual Paulista "Júlio Mesquita Filho", Faculdade de Engenharia de Guaratinguetá, Departamento de Engenharia Elétrica, Guaratinguetá-SP, Brazil. 
more such characteristics. Among the most used variable control charts are those that monitor the mean and range of the process (Costa et al., 2005).

When human subjectivity plays an important role in defining quality characteristics, traditional control charts cannot be applied since they require accurate data. By applying fuzzy logic to control charts, flexibility in control limits is possible, which is not practicable in traditional control charts, where control limits are more stringent. This fact gives managers more options and flexibility in dealing with production processes, markets and customers (Gulbay and Kahraman, 2007).

Traditional control charts are used when accurate data are available. However, data of this type are not always available, due to the level of uncertainty present in measuring instruments and human observations. Fuzzy logic, proposed by Zadeh (1965), is a branch of mathematics that allows a computer to model the real world in the same way people do. It provides a simple way of reasoning with vague, ambiguous and/or and imprecise information or knowledge. Therefore, the use of fuzzy control charts instead of the traditional control charts to analyze the variability in many processes is necessary (Kaya et al., 2017).

In one of the earliest studies of fuzzy control charts, Bradshaw $\operatorname{Jr}$ (1983) described the advantage of applying fuzzy limits on the economic design of control charts instead to traditional control charts. Wang \& Raz (1990) proposed an approach based on fuzzy set theory to construct attribute control charts from linguistic data. They presented four transformation methods that convert fuzzy sets associated with linguistic values into scalars. The representative values are plotted on the chart, maintaining the standard format of control charts, making it simpler to compare the two types of charts.

Gülbay et al. (2004) developed control charts for attributes using $\alpha$-cut. This approach enables determining tightness in inspection by selecting an appropriate level: the larger, the more rigorous the inspection. Senturk \& Erginel (2009) used transformation methods more specific to the $\alpha$ level fuzzy midrange to construct control charts of variables, with the charts $\bar{X}-R$ and $\bar{X}-S$ using $\alpha$-cut.

Alizadeh \& Ghomi (2011) developed fuzzy control charts for mean and range using four transformation methods involving triangular fuzzy numbers. The performance of the control charts was calculated in terms of average run length (ARL). They concluded that each transformation method has a different influence on performance of control charts for mean and range. They also found that the $\alpha$-level value has a significant influence on the performance of the control charts analyzed. The variation was considered only in the mean of the process and not in the magnitude of perturbation of the variability.

Moraditadi \& Avakhdarestani (2016) applied fuzzy set theory to control charts for individual values and moving range for fuzzy triangular and trapezoidal observations, and the results showed that the fuzzy control chart was more sensitive than the classic one, and also showed more consistent cases. In addition, the fuzzy method was more sensitive for trapezoidal than triangular 
numbers for this type of chart, which differs from the chart only for mean or mean and range that use sample data rather than individual data.

Kaya et al. (2017) suggested the application of the fuzzy control chart to individual values in order to increase the flexibility in the control limits, improving stock price variability analysis in the financial market. Senturk \& Antucheviciene (2017) presented the interval type-2 fuzzy $c$-control chart with an application to a food company.

Fuzzy set theory applied to control charts has been used from different perspectives and with different objectives, such as: to improve the performance of traditional control charts, since the use of fuzzy theory allows dealing with uncertainty, randomness and imprecision; and to propose new control charts for quality characteristics defined by linguistic variables, both for the univariate and multivariate cases (Fernández, 2017).

This article proposes a control chart based on fuzzy logic to monitor the mean and range of univariate processes as well as studies the performance of the chart. Disturbances in both the magnitude of the mean and the range are considered in order to obtain the average run length (ARL). The performance of the control chart is also measured by another parameter, the extra quadratic loss (EQL).

The comparisons between the traditional Shewhart control chart and the fuzzy control chart are performed by simulations using the following transformations: fuzzy median; $\alpha$-level fuzzy midrange; fuzzy average; and fuzzy mode. In this study, the $\alpha$-level fuzzy midrange transformation is used for the fuzzy $\bar{X}-R$ control chart and the $\bar{X}-R$ control chart.

There are not many works in the literature examining the performance of fuzzy control charts. Alizadeh \& Ghomi (2011) obtained the ARL for the fuzzy $\bar{X}$ and R control charts, considering only shifts in the process mean.

From the articles resulting from the database search for this work, we observed there were few works that have analyzed the performance of fuzzy control charts. In the last ten years, in the Scopus database, about 65 articles on the fuzzy control chart were found, and in relation to the fuzzy $\bar{X}$ - $R$ control chart studied here, only Alizadeh \& Ghomi (2011) obtained the ARL for this chart, but not in the correct way, because they took into account only the displacement in the mean and not the variability.

The application of fuzzy logic to the traditional control chart is interesting since observations close to control limits can cause false alarms with traditional control charts. Special causes that traditional control charts did not detect were detected in the fuzzy control chart. Fuzzy observations and fuzzy control charts may provide more flexibility to control a process, since quality experts can vary the degree of uncertainty inserted in the process and use $\alpha$ to vary the degree of requirement for inspection

This paper is organized as follows: Section 2 introduces some concepts about the $\alpha$-level fuzzy midrange transformation. The fuzzy $\bar{X}-R$ control chart is presented in Section 3. Some concepts about the efficiency of control charts are presented in Section 4. An example of application is 
illustrated in Section 5 and Section 6 presents the final considerations and suggestions for future research.

\section{FUZZY TRANSFORMATION TECHINIQUES}

\section{1 $\alpha$-level fuzzy midrange transformation}

To maintain the standard format of the control chart and to facilitate the plotting of observations, it is necessary to convert the fuzzy observations into representative values. That conversion can be accomplished by means of some transformation techniques. According to Wang \& Raz (1990), it can be performed as long as the result is intuitively representative of the range of the base variable included in the fuzzy set. It is noteworthy that according to these authors, there is no theoretical basis that supports the specific choice of any of the methods; the selection between them should be based mainly on the ease of calculation or the preference of the user.

In this work, we use the $\alpha$-level fuzzy midrange transformation for the fuzzy control charts $\bar{X}$ and $R$ (Senturk \& Erginel, 2009).

The $\alpha$-level fuzzy midrange transformation $f_{m r}^{\alpha}$ can be defined as the midpoint of the ends of the $\alpha$-cut. The $\alpha$-cut, denoted by $B^{\alpha}$, is a set of values that have degrees of membership greater than or equal to $\alpha$, where $a^{\alpha}$ and $c^{\alpha}$ the endpoints. Equation (1) describes this transformation.

$$
f_{m r}^{\alpha}=\frac{1}{2}\left(a^{\alpha}+c^{\alpha}\right)
$$

where $a^{\alpha}$ and $c^{\alpha}$ are given by equations (2) and (3).

$$
\begin{aligned}
& a^{\alpha}=a+\alpha(b-a) \\
& c^{\alpha}=c-\alpha(c-b)
\end{aligned}
$$

Applying the transformation to a sample $\mathrm{j}$ gives the statistic for each sample, called $S_{m r . j}^{\alpha}$, according to equation (4).

$$
S_{m r . j}^{\alpha}=\frac{\left(a_{j}+c_{j}\right)+\alpha\left[\left(b_{j}-a_{j}\right)-\left(c_{j}-b_{j}\right)\right]}{2}
$$

The $\alpha$-cut is defined as the degree of requirement for inspection of the process under analysis, so the higher the value of the $\alpha$-cut, the more rigorous the the inspection will be. The value is adopted according to the nature of the process and can vary from 0 to 1 (Gülbay et al., 2004).

In this paper, $\alpha=0.55, \alpha=0.65$ and $\alpha=0.95$ are used for the purpose of comparing the performance between the fuzzy control chart and the traditional control chart.

\section{$3 \quad$ FUZZY $\bar{X}$ AND $R$ CONTROL CHARTS}

In the traditional approach, the control of process averages or mean quality levels is usually performed by $\bar{X}$ charts. The process variability or dispersion can be controlled by a control chart 
for the range, called $R$ chart (Senturk \& Erginel, 2009). In this section, fuzzy $\bar{X}-R$ control charts are introduced.

The upper (UCL), lower (LCL) and center line (CL) limits for the chart $\bar{X}$ can be obtained by equations (5), (6) and (7).

$$
\begin{gathered}
U C L_{\bar{X}}=\overline{\bar{X}}+A_{2} \bar{R} \\
C L_{\bar{X}}=\overline{\bar{X}} \\
L C L_{\bar{X}}=\overline{\bar{X}}-A_{2} \bar{R}
\end{gathered}
$$

where $A_{2}$ is a coefficient that depends on the sample size $n$ and is defined by equation (8) (Montgomery, 2009).

$$
A_{2}=\frac{3}{d_{2} \sqrt{n}}
$$

where $d_{2}$ is a constant that depends on the sample size $n$; see Costa et al. (2005) for values.

The upper (UCL), lower (LCL) and the center line (CL) limits for the R chart can be obtained by equations (9), (10) and (11).

$$
\begin{aligned}
U C L_{R} & =D_{4} \bar{R} \\
C L_{R} & =\bar{R} \\
L C L_{R} & =D_{3} \bar{R}
\end{aligned}
$$

where $D_{3}$ and $D_{4}$ are coefficients defined by the following equations (Montgomery, 2009):

$$
\begin{aligned}
& D_{3}=1-\frac{3 d_{3}}{d_{2}} \\
& D_{4}=1+\frac{3 d_{3}}{d_{2}}
\end{aligned}
$$

where $d_{2}$ and $d_{3}$ are constants that depend on the sample size $n$; see Costa et al. (2005) for values. In fuzzy control charts, when one assumes that a quality characteristic is defined as "approximately $x$ ", this value should be converted into a triangular type fuzzy number $(a, b, c)$, as can be seen in Figure 1 (Kahraman \& Kaya, 2011).

In this study, the fuzzy numbers are represented as $\left(X_{a}, X_{b}, X_{c}\right)$ for each observation and the center line (CL) is calculated by means of the mean of these observations, as can be observed respectively in equations (14), (15) and (16), where $n$ is the size of the fuzzy sample and $m$ is the number of fuzzy samples.

$$
\begin{gathered}
\bar{X}_{k j}=\frac{\sum_{i=1}^{n} X_{k j i}}{n} ; k=a, b, c ; i=1.2, \ldots, n ; j=1.2, \ldots m, \\
\overline{\bar{X}}_{k j}=\frac{\sum_{j=1}^{m} \bar{X}_{k j}}{m} ; k=a, b, c ; j=1.2, \ldots m, \\
C L_{\bar{X}}=\left(\overline{\bar{X}}_{a}, \overline{\bar{X}}_{b}, \overline{\bar{X}}_{c}\right)=\left(\frac{\sum_{j=1}^{m} \bar{X}_{a j}}{m}, \frac{\sum_{j=1}^{m} \bar{X}_{b j}}{m}, \frac{\sum_{j=1}^{m} \bar{X}_{c j}}{m}\right)
\end{gathered}
$$




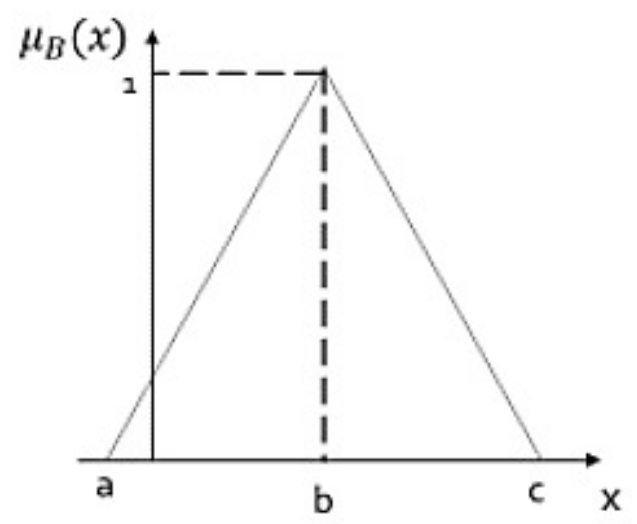

Figure 1 - Representation of a triangular fuzzy number.

Source: Adapted from Senturk \& Erginel (2009).

Once the maximum and minimum fuzzy observations have been determined, the range can be obtained according to equations (17), (18) and (19) (Kahraman et al., 2016).

$$
\begin{aligned}
& R_{a j}=X_{\max , a j}-X_{\min , c j} ; j=1.2, \ldots m, \\
& R_{b j}=X_{\max , b j}-X_{\min , b j} ; j=1.2, \ldots m, \\
& R_{c j}=X_{\max , c j}-X_{\min , a j} ; j=1.2, \ldots m,
\end{aligned}
$$

where $\left(X_{\max , a j}, X_{\max , b j}, X_{\max , c j}\right)$ is the maximum fuzzy number of the sample and $\left(X_{\min , a j}, X_{\min , b j}, X_{\min , c j}\right)$ is the minimum fuzzy number of the sample, so the mean range can be obtained according to equations (20), (21) and (22) (Senturk \& Erginel, 2009).

$$
\begin{aligned}
\bar{R}_{a} & =\frac{\sum R_{a j}}{m} \\
\bar{R}_{b} & =\frac{\sum R_{b j}}{m} \\
\bar{R}_{c} & =\frac{\sum R_{c j}}{m}
\end{aligned}
$$

The UCL, CL and LCL for the fuzzy $\bar{X}$ control chart can be obtained by:

$$
\begin{array}{r}
U C L_{\bar{X}}=\left(\overline{\bar{X}}_{a}, \overline{\bar{X}}_{b}, \overline{\bar{X}}_{c}\right)+A_{2}\left(\bar{R}_{a}, \bar{R}_{b}, \bar{R}_{c}\right) \\
C L_{\bar{X}}=\left(\overline{\bar{X}}_{a}, \overline{\bar{X}}_{b}, \overline{\bar{X}}_{c}\right) \\
L C L_{\bar{X}}=\left(\overline{\bar{X}}_{a}, \overline{\bar{X}}_{b}, \overline{\bar{X}}_{c}\right)-A_{2}\left(\bar{R}_{a}, \bar{R}_{b}, \bar{R}_{c}\right)
\end{array}
$$


By applying the $\alpha$-level fuzzy midrange transformation used in this study, it is possible to obtain (UCL), (CL) and (LCL) respectively for the fuzzy $\bar{X}$ control chart.

$$
\begin{gathered}
U C L_{m r-\bar{X}}^{\alpha}=\left(\frac{\overline{\bar{X}}_{a}^{\alpha}+\overline{\bar{X}}_{c}^{\alpha}}{2}\right)+A_{2}\left(\frac{\bar{R}_{a}^{\alpha}+\bar{R}_{c}^{\alpha}}{2}\right) \\
C L_{m r-\bar{X}}^{\alpha}=\left(\frac{\overline{\bar{X}}_{a}^{\alpha}+\overline{\bar{X}}_{c}^{\alpha}}{2}\right) \\
L C L_{m r-\bar{X}}^{\alpha}=\left(\frac{\overline{\bar{X}}_{a}^{\alpha}+\overline{\bar{X}}_{c}^{\alpha}}{2}\right)-A_{2}\left(\frac{\bar{R}_{a}^{\alpha}+\bar{R}_{c}^{\alpha}}{2}\right)
\end{gathered}
$$

The UCL, CL and LCL for the fuzzy control R chart can be obtained by:

$$
\begin{aligned}
U C L_{R} & =D_{4}\left(\bar{R}_{a}, \bar{R}_{b}, \bar{R}_{c}\right) \\
C L_{R} & =\left(\bar{R}_{a}, \bar{R}_{b}, \bar{R}_{c}\right) \\
L C L_{R} & =D_{3}\left(\bar{R}_{a}, \bar{R}_{b}, \bar{R}_{c}\right)
\end{aligned}
$$

By applying the $\alpha$-level fuzzy midrange transformation used in this study, it is possible to obtain (UCL), (CL) and (LCL) respectively for the fuzzy control R chart.

$$
\begin{gathered}
U C L_{m r-R}^{\alpha}=D_{4}\left(\frac{\bar{R}_{a}^{\alpha}+\bar{R}_{c}^{\alpha}}{2}\right) \\
C L_{m r-R}^{\alpha}=\left(\frac{\bar{R}_{a}^{\alpha}+\bar{R}_{c}^{\alpha}}{2}\right) \\
L C L_{m r-R}^{\alpha}=D_{3}\left(\frac{\bar{R}_{a}^{\alpha}+\bar{R}_{c}^{\alpha}}{2}\right)
\end{gathered}
$$

The values of $\overline{\bar{X}}_{a}^{\alpha}, \overline{\bar{X}}_{c}^{\alpha}, \bar{R}_{a}^{\alpha}$ and $\bar{R}_{c}^{\alpha}$ can respectively be obtained by:

$$
\begin{gathered}
\overline{\bar{X}}_{a}^{\alpha}=\overline{\bar{X}}_{a}+\alpha\left(\overline{\bar{X}}_{b}-\overline{\bar{X}}_{a}\right) \\
\overline{\bar{X}}_{c}^{\alpha}=\overline{\bar{X}}_{c}-\alpha\left(\overline{\bar{X}}_{c}-\overline{\bar{X}}_{b}\right) \\
\bar{R}_{a}^{\alpha}=\bar{R}_{a}+\alpha\left(\bar{R}_{b}-\bar{R}_{a}\right) \\
\bar{R}_{c}^{\alpha}=\bar{R}_{c}-\alpha\left(\bar{R}_{c}-\bar{R}_{b}\right)
\end{gathered}
$$

The monitoring statistic of the fuzzy chart $\bar{X}$ for a given sample $j$ is given by:

$$
S_{m r-\overline{X j}}^{\alpha}=\frac{\left(\bar{X}_{a j}+\bar{X}_{c j}\right)+\alpha\left[\left(\bar{X}_{b j}-\bar{X}_{a j}\right)-\left(\bar{X}_{c j}-\bar{X}_{b j}\right)\right]}{2}
$$


Therefore, the process control condition can be defined as:

$$
\left\{\begin{array}{l}
\text { In control for } U C L_{m r-\bar{X}}^{\alpha} \leq S_{m r-\overline{X j}}^{\alpha} \leq L C L_{m r-\bar{X}}^{\alpha} \\
\text { Outside control otherwise }
\end{array}\right.
$$

The monitoring statistic of the fuzzy R chart for a given sample $j$ is given by:

$$
S_{m r-R j}^{\alpha}=\frac{\left(R_{a j}+R_{c j}\right)+\alpha\left[\left(R_{b j}-R_{a j}\right)-\left(R_{c j}-R_{b j}\right)\right]}{2}
$$

Therefore, the process control condition can be defined as:

$$
\left\{\begin{array}{l}
\text { In control for } U C L_{m r-R}^{\alpha} \leq S_{m r-R j}^{\alpha} \leq L C L_{m r-R}^{\alpha} \\
\text { Outside control otherwise }
\end{array}\right.
$$

\section{CONTROL CHART PERFORMANCE}

In this section, the traditional Shewhart control chart and the fuzzy control chart are compared based on their performance. This is measured by the average run length (ARL) and extra quadratic loss (EQL). The charts are more efficient the lower the ARL value, since in the control charts of $\bar{X}-R$ the samples are collected at constant time intervals (Costa et al., 2005).

As an efficiency comparison between control chart types, one must first adjust the control factor $(k)$ of each chart separately, so that when the process is in control, the two charts have the same number of samples until the false alarm $\left(\mathrm{ARL}_{0}\right)$. From the moment that the values of $\left(\mathrm{ARL}_{0}\right)$ are equal, a difference of $\delta$ standard deviations in the process mean and a shift of $\lambda$ in the process range is simulated and the ARL values of the traditional control chart with the corresponding fuzzy control chart. The one with the lowest ARL value is the most efficient for this particular situation. Therefore, the most efficient charts must have high values of $\mathrm{ARL}_{0}$, that is, few false alarms and low ARL values, to quickly detect perturbations in the mean and range of the process (Fang et al., 2013).

In accordance with Costa \& Rahim (2006) and Costa et al. (2009), the objective is to monitor any assignable cause that shifts the in-control value of the process mean $\mu_{0}$ to $\mu_{1}=\mu_{0} \pm \delta \sigma_{\bar{X}}$ and/or increases the in-control standard deviation $\sigma_{0}$ to $\sigma_{1}=\lambda \sigma_{0}$, where $\gamma$ is the magnitude of the increase in variability.

The performance of the $\bar{X}-R$ charts is also measured by the EQL, according to Wu et al. (2008), given by equation (41):

$$
E Q L=\frac{\sigma^{2}{ }_{0}}{\delta_{\max } \cdot\left(\lambda_{\max }-1\right)} \cdot \int_{0}^{\delta_{\max }} \int_{1}^{\lambda_{\max }}\left(\delta^{2}+\lambda^{2}-1\right) A R L(\delta, \lambda) \cdot d \delta \cdot d \lambda
$$

where $\operatorname{ARL}(\delta, \lambda)$ is the ARL computed with $\mu_{1}$ and $\sigma_{1}, \delta_{\max }$ is the upper bound of $\delta$ and $\lambda_{\max }$ is the upper bound of $\lambda$; see Ou et al. (2011) and Machado \& Costa (2014) for details. 
In this paper, the simulations to calculate the ARL were performed for sample size 5 and the following values for alpha, $\alpha=0.55, \alpha=0.65$ and $\alpha=0.95$, considering the simulation of 10000 second replicates (Domangue \& Patch, 1991).

For the calculation of the reduction percentage between the results obtained from the fuzzy control chart and the results from the traditional chart, the following equation was used:

$$
\text { Percentage Reduction }(P R)=100 \% \frac{A R L_{F}-A R L_{T}}{A R L_{T}}
$$

where $A R L_{T}$ is the average run length of the traditional chart signal and $A R L_{F}$ is the average run length of the fuzzy control chart signal.

Tables 1, 2 and 3 report the ARL values of the traditional control chart and the ARL of the fuzzy control chart for sample size 5 and values of $\alpha=0.55, \alpha=0.65$ and $\alpha=0.95$ respectively, where $\delta$ is the magnitude of the perturbation of the mean and $\lambda$ is the magnitude of the perturbation of the variability.

Note that the $A R L_{F}$ values are smaller than the $A R L_{T}$ values. From equation (42), it can be seen that the largest reduction percentage between $A R L_{F}$ for $\alpha=0.55$ and $A R L_{T}$ is $2.26 \%$ for $\delta$ of 0.6 and $\lambda=1.4$. For $\alpha=0.65$, the greatest reduction percentage between $A R L_{F}$ and $A R L_{T}$ is $1.87 \%$ for $\delta$ of 0.4 and $\lambda=1$ and for $\alpha=0.95$ it is $1.90 \%$ for $\delta$ of 1.2 and $\lambda=1.3$.

Tables 1, 2 and 3 show that the reduction of ARL values is not very significant, but it still true that the application of fuzzy logic to traditional control charts is interesting because fuzzy numbers and fuzzy control charts offer more flexibility in process control, since the expert can give an opinion and vary the degree of uncertainty, as well as choose which $\alpha$ to use in the process according to the importance of the inspection, where the closer to 1 , the more demanding the inspection will be.

Regarding EQL, Tables 1, 2 and 3 show that the value the of EQL of the fuzzy control chart for any $\alpha$ value is smaller than the EQL value of the traditional control chart. Also, the value of EQL of the traditional chart is about 269.5 and of the fuzzy control chart it is on average around 267.3 for $\alpha$ values $=0.55,0.65$ and 0.95 . The difference in the values of ARL and EQL for fuzzy charts and traditional Shewhart charts is subtle, but it does exist, and applying fuzzy logic to traditional control charts makes process monitoring closer to reality, since uncertainty is always present in measurements

Such application is valid because it allows the operator to be more confident in making the decision whether the process is in or outside control.

\section{ILLUSTRATIVE EXAMPLE}

In this section, an example is provided to illustrate the detection capability of the fuzzy $\bar{X}-\mathrm{R}$ control chart in relation to the traditional chart. In order to do this, we consider a milk bag filling process where the volume of the product of each bag must be permanently monitored in order to avoid the occurrence of excesses (which increase the risk of the bags bursting during handling 
Table 1 - Comparison of ARL of traditional control chart and fuzzy control for $\alpha=0.55$.

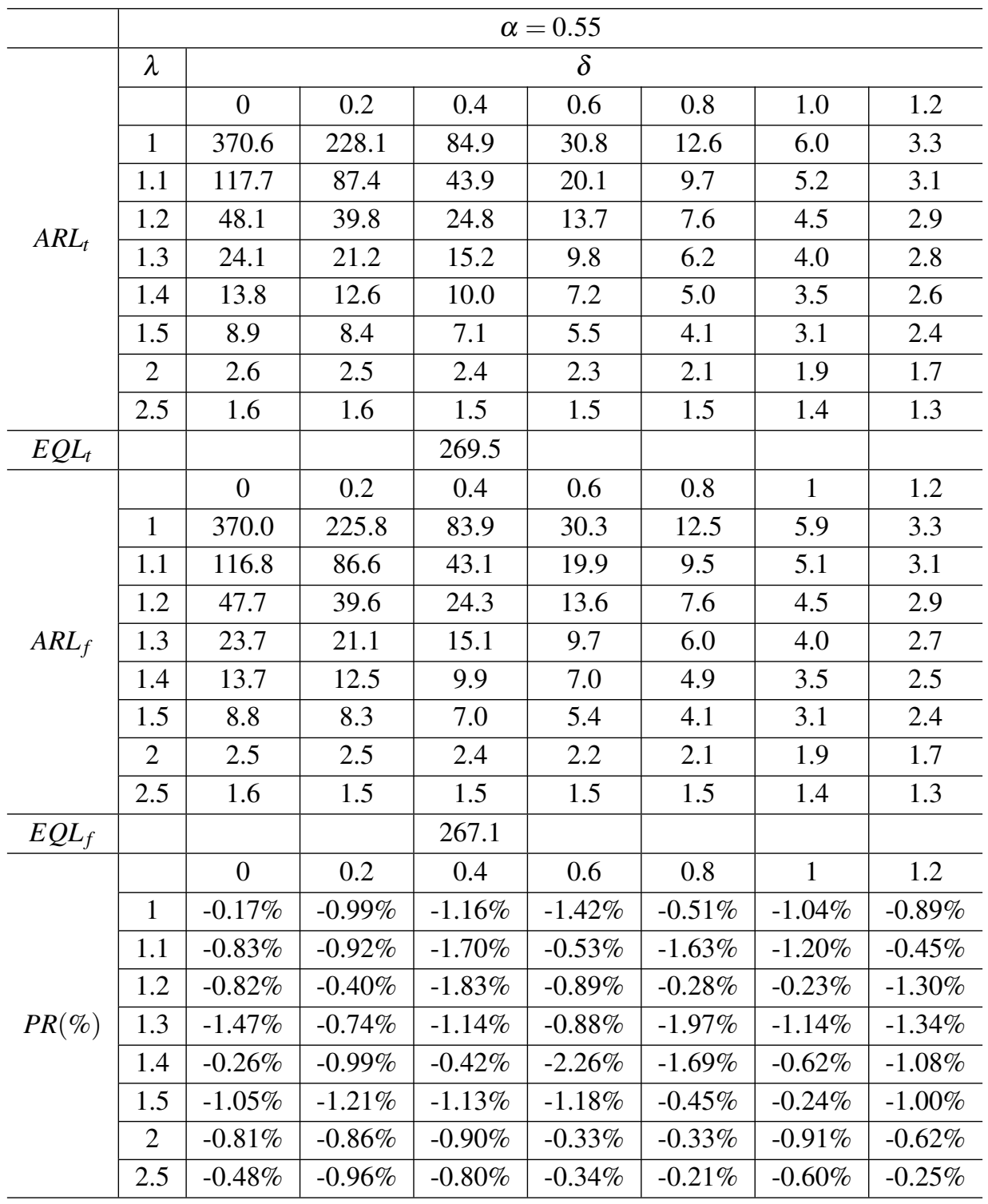

and transportation) or insufficiency (which leads to the risk of the company being fined). The main tool used to monitor processes and signals the presence of special causes is the control chart. When the process is in control, the mean is $1000 \mathrm{ml}$ and the standard deviation is $4 \mathrm{ml}$ (Costa et al., 2005).

Twenty-five sample bags were removed and the volume of each item was measured, as shown in Table 4. First, the traditional control chart was constructed to monitor the volume of the bags. 
Table 2 - Comparison of ARL between traditional control chart and fuzzy control chart for $\alpha=0.65$.

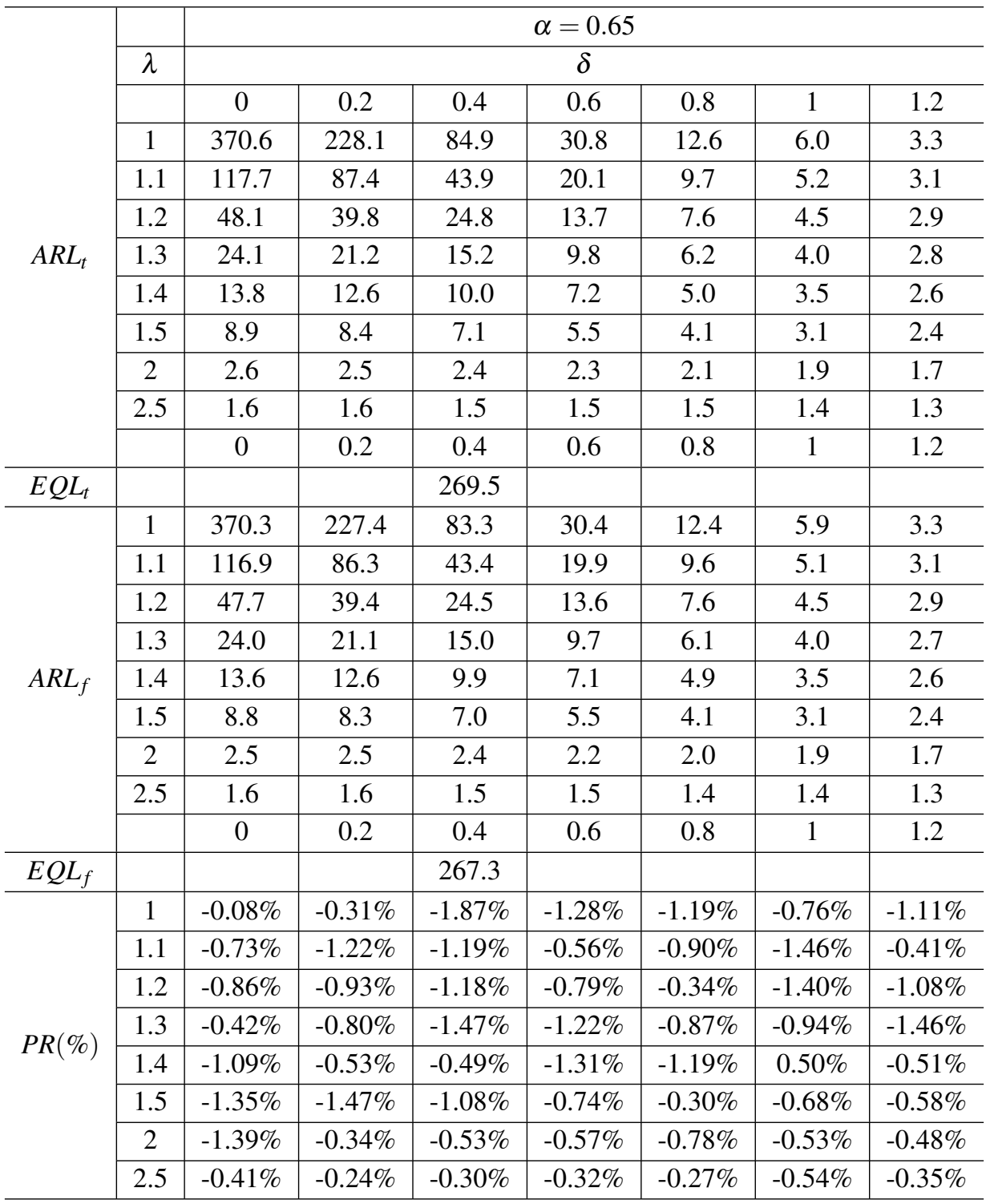

According to Costa et al. (2005), the mean chart is affected by both special causes that alter the mean of the process, and by special causes that affect the dispersion, so the mean chart can only be constructed when the process is stable and adjusted.

For the process of the present work, the $12^{\text {th }}$ and $13^{\text {th }}$ samples must be withdrawn, since they are above the control limit of the range and the limit of control of the mean. Thus, the limits are recalculated with the remaining 23 observations for the mean control chart and with 24 observations for the range control chart, obtaining the final values for the mean and range limits by equations 
Table 3 - Comparison of ARL between traditional control chart and fuzzy control chart for $\alpha=0.95$.

\begin{tabular}{|c|c|c|c|c|c|c|c|c|}
\hline & & \multicolumn{7}{|c|}{$\alpha=0.95$} \\
\hline \multirow{10}{*}{$A R L_{t}$} & \multirow[t]{2}{*}{$\lambda$} & \multicolumn{7}{|c|}{$\delta$} \\
\hline & & 0 & 0.2 & 0.4 & 0.6 & 0.8 & 1 & 1.2 \\
\hline & 1 & 370.6 & 228.1 & 84.9 & 30.8 & 12.6 & 6.0 & 3.3 \\
\hline & 1.1 & 117.7 & 87.4 & 43.9 & 20.1 & 9.7 & 5.2 & 3.1 \\
\hline & 1.2 & 48.1 & 39.8 & 24.8 & 13.7 & 7.6 & 4.5 & 2.9 \\
\hline & 1.3 & 24.1 & 21.2 & 15.2 & 9.8 & 6.2 & 4.0 & 2.8 \\
\hline & 1.4 & 13.8 & 12.6 & 10.0 & 7.2 & 5.0 & 3.5 & 2.6 \\
\hline & 1.5 & 8.9 & 8.4 & 7.1 & 5.5 & 4.1 & 3.1 & 2.4 \\
\hline & 2 & 2.6 & 2.5 & 2.4 & 2.3 & 2.1 & 1.9 & 1.7 \\
\hline & 2.5 & 1.6 & 1.6 & 1.5 & 1.5 & 1.5 & 1.4 & 1.3 \\
\hline$E Q L_{t}$ & & & & 269.5 & & & & \\
\hline \multirow{9}{*}{$A R L_{f}$} & & 0 & 0.2 & 0.4 & 0.6 & 0.8 & 1 & 1.2 \\
\hline & 1 & 370.5 & 226.9 & 84.5 & 30.5 & 12.4 & 5.9 & 3.3 \\
\hline & 1.1 & 116.9 & 86.8 & 43.5 & 19.9 & 9.5 & 5.1 & 3.1 \\
\hline & 1.2 & 47.9 & 39.3 & 24.6 & 13.6 & 7.5 & 4.5 & 2.9 \\
\hline & 1.3 & 23.7 & 21.1 & 15.0 & 9.7 & 6.1 & 4.0 & 2.7 \\
\hline & 1.4 & 13.7 & 12.5 & 9.9 & 7.2 & 5.0 & 3.5 & 2.5 \\
\hline & 1.5 & 8.9 & 8.3 & 7.0 & 5.5 & 4.1 & 3.1 & 2.4 \\
\hline & 2 & 2.6 & 2.5 & 2.4 & 2.2 & 2.0 & 1.8 & 1.7 \\
\hline & 2.5 & 1.6 & 1.5 & 1.5 & 1.5 & 1.4 & 1.4 & 1.3 \\
\hline$E Q L_{f}$ & & & & 267.3 & & & & \\
\hline \multirow{9}{*}{$P R(\%)$} & & 0 & 0.2 & 0.4 & 0.6 & 0.8 & 1 & 1.2 \\
\hline & 1 & $-0.04 \%$ & $-0.52 \%$ & $-0.49 \%$ & $-0.93 \%$ & $-1.15 \%$ & $-1.13 \%$ & $-1.68 \%$ \\
\hline & 1.1 & $-0.73 \%$ & $-0.72 \%$ & $-0.81 \%$ & $-0.59 \%$ & $-1.70 \%$ & $-1.67 \%$ & $-0.61 \%$ \\
\hline & 1.2 & $-0.38 \%$ & $-1.15 \%$ & $-0.49 \%$ & $-0.77 \%$ & $-1.79 \%$ & $-0.94 \%$ & $-1.48 \%$ \\
\hline & 1.3 & $-1.42 \%$ & $-0.64 \%$ & $-1.41 \%$ & $-1.07 \%$ & $-0.75 \%$ & $-1.32 \%$ & $-1.90 \%$ \\
\hline & 1.4 & $-0.80 \%$ & $-1.13 \%$ & $-0.62 \%$ & $-0.41 \%$ & $-0.83 \%$ & $-1.36 \%$ & $-1.38 \%$ \\
\hline & 1.5 & $-0.31 \%$ & $-1.21 \%$ & $-0.84 \%$ & $-0.78 \%$ & $-0.93 \%$ & $-0.58 \%$ & $-0.85 \%$ \\
\hline & 2 & $-0.22 \%$ & $-0.53 \%$ & $-0.46 \%$ & $-0.84 \%$ & $-1.12 \%$ & $-1.41 \%$ & $-0.88 \%$ \\
\hline & 2.5 & $-0.36 \%$ & $-0.42 \%$ & $-0.53 \%$ & $-0.68 \%$ & $-0.34 \%$ & $-0.29 \%$ & $-1.14 \%$ \\
\hline
\end{tabular}

(5), (7), (9) and (11), respectively: $U C L_{\bar{X}}=1005.7323, L C L_{\bar{X}}=993.6538, U C L_{R}=22.1265$ and $L C L_{R}=0$.

In order to study the behavior of the chart in an outside control situation, a further 10 samples were generated with $\delta$ of 1 in the process mean and $\lambda$ of 1.5 in the range. Table 5 reports the set of observations. 
Table 4 - Volume of milk bags, their mean and range.

\begin{tabular}{c|c|c|c|c|c|c|c}
\hline Sample Number & $X_{1}$ & $X_{2}$ & $X_{3}$ & $X_{4}$ & $X_{5}$ & Mean & Range \\
\hline 1 & 1004.6 & 997.3 & 1003 & 1005.9 & 995.8 & 1001.3 & 10.1 \\
\hline 2 & 1001.6 & 1008.6 & 997.9 & 1001.3 & 999.1 & 1001.7 & 10.7 \\
\hline 3 & 999.1 & 992.6 & 1001.1 & 1001.6 & 1002.9 & 999.5 & 10.3 \\
\hline 4 & 1007.9 & 997.5 & 991.3 & 997.8 & 1000.8 & 999.1 & 16.6 \\
\hline 5 & 999.5 & 995.6 & 1004.3 & 995.6 & 991.4 & 997.3 & 12.9 \\
\hline 6 & 1003.3 & 996.8 & 997.2 & 993.6 & 1000.1 & 998.2 & 9.7 \\
\hline 7 & 999.7 & 1012.1 & 995.2 & 1001.8 & 1002.2 & 1002.2 & 16.9 \\
\hline 8 & 1000.1 & 995.3 & 990 & 997.5 & 1003.2 & 997.2 & 13.2 \\
\hline 9 & 1004.3 & 1001.4 & 1001.6 & 999.1 & 996.4 & 1000.6 & 7.9 \\
\hline 10 & 999 & 995.8 & 989.9 & 995.1 & 1002.8 & 996.5 & 12.9 \\
\hline 11 & 1003.2 & 1004.4 & 993.5 & 994.6 & 997.6 & 998.7 & 10.9 \\
\hline 12 & 996.2 & 1017.3 & 993.6 & 996.5 & 1003.7 & 1001.5 & 23.7 \\
\hline 13 & 1014 & 1008.9 & 1004.1 & 1007.9 & 1000.7 & 1007.1 & 13.3 \\
\hline 14 & 1002.2 & 996.6 & 1002.7 & 1004.2 & 1001.8 & 1001.5 & 7.6 \\
\hline 15 & 998.3 & 997.5 & 1006.1 & 996.5 & 998.1 & 999.3 & 9.6 \\
\hline 16 & 995.8 & 1000.8 & 999.1 & 1002.5 & 1001 & 999.8 & 6.7 \\
\hline 17 & 1004.1 & 1003 & 1004.8 & 997.9 & 999.9 & 1001.9 & 6.9 \\
\hline 18 & 1000.1 & 994.9 & 1000.1 & 1004.9 & 997.3 & 999.5 & 10.0 \\
\hline 19 & 1000.2 & 996.1 & 998 & 1006.1 & 999.4 & 1000.0 & 10.0 \\
\hline 20 & 1002.3 & 999 & 1000.8 & 1000.7 & 998 & 1000.2 & 4.3 \\
\hline 21 & 998.3 & 998.1 & 1004.2 & 1002.1 & 991.3 & 998.8 & 12.9 \\
\hline 22 & 997.1 & 1000.7 & 999.8 & 1000.6 & 1001.7 & 1000.0 & 4.6 \\
\hline 24 & 1003.6 & 996.1 & 1001.4 & 998 & 991.8 & 998.2 & 11.8 \\
\hline 25 & 999.9 & 1006.4 & 1005.1 & 999.8 & 1003 & 1002.8 & 6.6 \\
\hline & 1007.3 & 999.8 & 992.5 & 996.2 & 998.2 & 998.8 & 14.8 \\
\hline 12 & & 504 & & & & \\
\hline 14 & 10.9 &
\end{tabular}

Source: Costa et al. (2005).

By calculating the mean and range of the observations, it was possible to elaborate Tables 6 and 7, which demonstrate the process control conditions. Table 6 shows that samples 27, 30 and 32 exceed the value of the upper control limit and therefore are outside control; in addition, sample 35 is near the upper limit.

For Table 7, which represents the process control conditions for the range control chart, all the sample points are within the previously calculated control limits.

In order to construct the fuzzy control charts and compare them with the traditional chart, fuzzy numbers were generated based on the set of observations in Tables 4 and 5. Uncertainty was added, which can be attributed to the measuring instrument, randomly following the uniform distribution ranging from 0 to 1 , according to experts, as can be seen in Table 8 . 
Table 5 - Samples with process outside control.

\begin{tabular}{c|c|c|c|c|c}
\hline Sample Number & $X_{1}$ & $X_{2}$ & $X_{3}$ & $X_{4}$ & $X_{5}$ \\
\hline 1 & 996.0657 & 999.3373 & 994.6958 & 1001.5817 & 998.3923 \\
\hline 2 & 1009.4533 & 1003.0522 & 1004.7023 & 1016.5194 & 1011.7945 \\
\hline 3 & 1002.6980 & 1006.9822 & 992.1539 & 1000.1566 & 997.9927 \\
\hline 4 & 998.4566 & 1011.0536 & 1000.9139 & 1004.0916 & 1008.8012 \\
\hline 5 & 1010.1670 & 1007.5547 & 996.7948 & 1010.0667 & 1005.1272 \\
\hline 6 & 999.7326 & 1001.7451 & 998.2166 & 1000.9928 & 1003.3693 \\
\hline 7 & 1009.8046 & 996.6570 & 1013.1134 & 1002.4216 & 1017.8025 \\
\hline 8 & 1003.0475 & 1003.3703 & 1006.6138 & 1005.7635 & 1001.5398 \\
\hline 9 & 994.8559 & 1011.7320 & 1008.2916 & 1002.1707 & 1003.2524 \\
\hline 10 & 1002.2537 & 1011.7732 & 1005.6364 & 1004.8856 & 1004.0810 \\
\hline
\end{tabular}

Source: Adapted from Costa et al. (2005).

Table 6 - Mean values and comparison with control limits.

\begin{tabular}{c|c|c|c|c|c}
\hline $\begin{array}{c}\text { Sample } \\
\text { Number }\end{array}$ & Mean & $\begin{array}{c}993.6538 \leq \\
\text { Mean } \leq 1005.7323\end{array}$ & $\begin{array}{c}\text { Sample } \\
\text { Number }\end{array}$ & Mean & $\begin{array}{c}993.6538 \leq \\
\text { Mean } \leq 1005.7323\end{array}$ \\
\hline 1 & 1001.3200 & In control & 19 & 999.9600 & In control \\
\hline 2 & 1001.7000 & In control & 20 & 1000.1600 & In control \\
\hline 3 & 999.4600 & In control & 21 & 998.8000 & In control \\
\hline 4 & 999.0600 & In control & 22 & 999.9800 & In control \\
\hline 5 & 997.2800 & In control & 23 & 998.1800 & In control \\
\hline 6 & 998.2000 & In control & 24 & 1002.8400 & In control \\
\hline 7 & 1002.2000 & In control & 25 & 998.8000 & In control \\
\hline 8 & 997.2200 & In control & 26 & 998.0146 & In control \\
\hline 9 & 1000.5600 & In control & 27 & 1009.1043 & Outside control \\
\hline 10 & 996.5200 & In control & 28 & 999.9967 & In control \\
\hline 11 & 998.6600 & In control & 29 & 1004.6634 & In control \\
\hline 12 & - & - & 30 & 1005.9421 & Outside control \\
\hline 13 & - & - & 31 & 1000.8113 & In control \\
\hline 14 & 1001.5000 & In control & 32 & 1007.9598 & Outside control \\
\hline 15 & 999.3000 & In control & 33 & 1004.0670 & In control \\
\hline 16 & 999.8400 & In control & 34 & 1004.0605 & In control \\
\hline 17 & 1001.9400 & In control & 35 & 1005.7260 & In control \\
\hline 18 & 999.4600 & In control & - & - & - \\
\hline & & & & & \\
\hline
\end{tabular}

From this dataset, the limits were calculated using the first 23 samples in control using equations (26), (28), (32) and (34) for $\alpha=0.95$, since like in the traditional chart it was necessary to withdraw samples number 12 and 13 because they made the process unstable, thus obtaining 
Table 7 - Range values and comparison with control limits.

\begin{tabular}{c|c|c|c|c|c}
\hline $\begin{array}{c}\text { Sample } \\
\text { Number }\end{array}$ & Range & $0 \leq$ Range $\leq 22.1265$ & $\begin{array}{c}\text { Sample } \\
\text { Number }\end{array}$ & Range & $0 \leq$ Range $\leq 22.1265$ \\
\hline 1 & 10.1000 & In control & 19 & 10.0000 & In control \\
\hline 2 & 10.7000 & In control & 20 & 4.3000 & In control \\
\hline 3 & 10.3000 & In control & 21 & 12.9000 & In control \\
\hline 4 & 16.6000 & In control & 22 & 4.6000 & In control \\
\hline 5 & 12.9000 & In control & 23 & 11.8000 & In control \\
\hline 6 & 9.7000 & In control & 24 & 6.6000 & In control \\
\hline 7 & 16.9000 & In control & 25 & 14.8000 & In control \\
\hline 8 & 13.2000 & In control & 26 & 6.8858 & In control \\
\hline 9 & 7.9000 & In control & 27 & 13.4672 & In control \\
\hline 10 & 12.9000 & In control & 28 & 14.8283 & In control \\
\hline 11 & 10.9000 & In control & 29 & 12.5970 & In control \\
\hline 12 & - & - & 30 & 13.3722 & In control \\
\hline 13 & 13.3000 & In control & 31 & 5.1528 & In control \\
\hline 14 & 7.6000 & In control & 32 & 21.1455 & In control \\
\hline 15 & 9.6000 & In control & 33 & 5.0740 & In control \\
\hline 16 & 6.7000 & In control & 34 & 16.8760 & In control \\
\hline 17 & 6.9000 & In control & 35 & 9.5195 & In control \\
\hline 18 & 10.0000 & In control & - & - & - \\
\hline & & & & & \\
\hline
\end{tabular}

the following values of control limits for mean and range respectively: $U C L_{\bar{X}}^{0.95}=1005.7229$, $L C L_{\bar{X}}^{0.95}=993.6406, U C L_{R}^{0.95}=22.1334$ and $L C L_{R}^{0.95}=0$.

By means of equations (39) and (40), it was possible to calculate the values of the statistics $S_{m r-\overline{X j}}^{\alpha}$ and $S_{m r-R j}^{\alpha}$ and thus construct Tables 9 and 10, which demonstrate the process control conditions of the fuzzy control chart for the mean and range with $\alpha=0.95$ respectively.

Table 9 shows that samples 27, 30, 32 and 35 exceed the value of the upper control limit. Table 6 shows that sample 35 does is not outside control in the traditional chart, whereas in the fuzzy control chart for $\alpha=0.95$ it exceeds the upper control limit.

Table 10 indicates that for the fuzzy control chart for range, all the sample points lie within previously calculated control limits, is also the case of the traditional control chart.

This illustrative example demonstrates that applying fuzzy control charts that use more process information can help improve productivity by detecting abnormal process changes on average slightly faster than Shewhart control charts, since sample 35 is not outside control in the traditional control chart $\bar{X}$ and is outside control in the fuzzy control chart $\bar{X}$. 


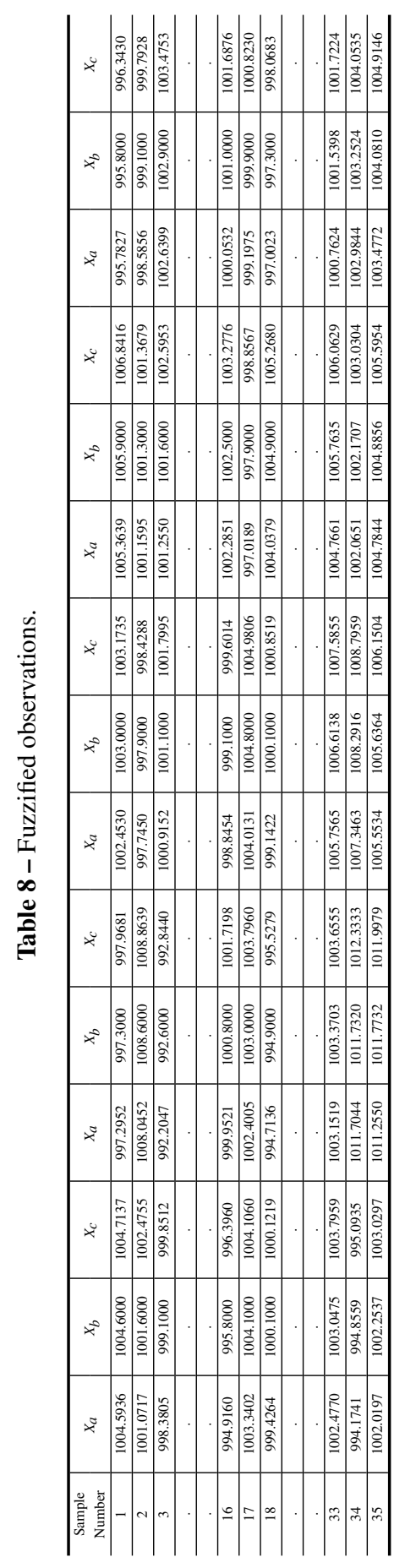


Table 9 - Statistical values $S_{m r-}^{\alpha} \overline{X j}$ and comparison with the limits.

\begin{tabular}{c|c|c|c|c|c}
\hline $\begin{array}{c}\text { Sample } \\
\text { Number }\end{array}$ & $S_{m r-\overline{X j}}^{0.95}$ & $\begin{array}{c}993.6406 \leq S_{m r-\overline{X j}}^{0.95} \\
\leq 1005.7229\end{array}$ & $\begin{array}{c}\text { Sample } \\
\text { Number }\end{array}$ & $S_{m r-\overline{X j}}^{0.95}$ & $\begin{array}{c}993.6406 \leq S_{m r-\overline{X j}}^{0.95} \\
\leq 1005.7229\end{array}$ \\
\hline 1 & 1001.3266 & In control & 19 & 999.9717 & In control \\
\hline 2 & 1001.7027 & In control & 20 & 1000.1558 & In control \\
\hline 3 & 999.4668 & In control & 21 & 998.8004 & In control \\
\hline 4 & 999.0571 & In control & 22 & 999.9837 & In control \\
\hline 5 & 997.2798 & In control & 23 & 998.1759 & In control \\
\hline 6 & 998.1956 & In control & 24 & 1002.8381 & In control \\
\hline 7 & 1002.1977 & In control & 25 & 998.7996 & In control \\
\hline 8 & 997.2102 & In control & 26 & 998.0160 & In control \\
\hline 9 & 1000.5583 & In control & 27 & 1009.1113 & Outside control \\
\hline 10 & 996.5203 & In control & 28 & 1000.0053 & In control \\
\hline 11 & 998.6569 & In control & 29 & 1004.6633 & In control \\
\hline 12 & - & - & 30 & 1005.9379 & Outside control \\
\hline 13 & - & - & 31 & 1000.8069 & In control \\
\hline 14 & 1001.4966 & In control & 32 & 1007.9536 & Outside control \\
\hline 15 & 999.2980 & In control & 33 & 1004.0623 & In control \\
\hline 16 & 999.8417 & In control & 34 & 1004.0654 & In control \\
\hline 17 & 1001.9357 & In control & 35 & 1005.7336 & Outside control \\
\hline 18 & 999.4578 & In control & - & - & - \\
\hline
\end{tabular}

Table 10 - Statistical values $S_{m r-R j}^{\alpha}$ and comparison with the limits.

\begin{tabular}{c|c|c|c|c|c}
\hline $\begin{array}{c}\text { Sample } \\
\text { Number }\end{array}$ & $S_{m r-R j}^{0.95}$ & $0 \leq S_{m r-R j}^{0.95} \leq 22.333$ & $\begin{array}{c}\text { Sample } \\
\text { Number }\end{array}$ & $S_{m r-R j}^{0.95}$ & $0 \leq S_{m r-R j}^{0.95} \leq 22.333$ \\
\hline 1 & 10.0970 & In control & 19 & 9.9858 & In control \\
\hline 2 & 10.6834 & In control & 20 & 4.3240 & In control \\
\hline 3 & 10.3117 & In control & 21 & 12.9080 & In control \\
\hline 4 & 16.6022 & In control & 22 & 4.6100 & In control \\
\hline 5 & 12.8866 & In control & 23 & 11.7878 & In control \\
\hline 6 & 9.6985 & In control & 24 & 6.6029 & In control \\
\hline 7 & 16.9243 & In control & 25 & 14.8065 & In control \\
\hline 8 & 13.2202 & In control & 26 & 6.8668 & In control \\
\hline 9 & 7.9203 & In control & 27 & 13.4734 & In control \\
\hline 10 & 12.9265 & In control & 28 & 14.8514 & In control \\
\hline 11 & 10.8977 & In control & 29 & 12.5822 & In control \\
\hline 12 & - & In control & 31 & 5.1656 & In control \\
\hline 13 & 13.2984 & In control \\
\hline 14 & 7.5990 & In control & 32 & 21.1559 & In control \\
\hline 15 & 9.6064 & In control & 33 & 5.0917 & In control \\
\hline 16 & 6.7213 & In control & 34 & 16.9015 & In control \\
\hline 17 & 6.8830 & In control & 35 & 9.4986 & In control \\
\hline 18 & 9.9766 & In control & - & - & - \\
\hline
\end{tabular}

\section{CONCLUDING REMARKS AND FUTURE RESEARCH}

In this work, fuzzy logic was applied to control charts $\bar{X}$-R, using the $\alpha$-level fuzzy midrange transformation. The observations of each sample were transformed into triangular fuzzy numbers to add uncertainties. Using fuzzy arithmetic, the mean and range of each sample were calculated after the transformation was applied, obtaining the representative values, thus constructing the fuzzy $\bar{X}$-R control charts. 
In order to compare the traditional and fuzzy control charts, their detection powers were verified by the average run length (ARL) and extra quadratic loss (EQL). We observed that the fuzzy control charts for all values of $\alpha$ had better performance than the traditional control chart, since they presented lower values of ARL. Although the ARL values were close to the values of the traditional control chart, there was some reduction, even if small, with the application of fuzzy logic.

For future research, we can suggest a study of sampling schemes for fuzzy control charts by variables, as well as a scenario analysis about which sampling scheme should be adopted and use of special run rules to obtain greater detection power.

\section{ACKNOWLEDGMENTS}

This study was financed in part by Coordenação de Aperfeiçoamento de Pessoal de Nvel Superior - Brasil (CAPES) - Finance Code 001.

\section{REFERENCES}

[1] Alizadeh HM \& GHomi SMT. 2011. Fuzzy development of Mean and Range control charts using statistical properties of different representative values. Journal of Intelligent \& Fuzzy Systems, 22(5): 253-265.

[2] Bradshaw JR CW. 1983. A fuzzy set theoretic interpretation of economic control limits. European Journal of Operational Research, 13(4): 403-408.

[3] Costa AFB, De Magalhães MS \& Epprecht EK. 2009. Monitoring the process mean and variance using a synthetic control chart with two-stage testing. International Journal of Production Research, 47(18): 5067-5086.

[4] Costa AFB, Epprecht EK \& CARpinetti LCR. 2005. Controle estatístico de qualidade. São Paulo: Editora Atlas.

[5] Costa AFB \& Rahim MA. 2006. A Synthetic Chart for Monitoring the Process Mean and Variance. International Journal in Quality in Maintenance Engineering, 12(1): 8188 .

[6] Domangue R \& Patch SC. 1991. Some omnibus exponentially weighted moving average statistical process monitoring schemes. Technometrics, 33(3): 299-313.

[7] Fang J, Wang H \& \& Deng W. 2013. Design of EWMA Control Charts for Assuring Predetermined Production Process Quality. Research Journal of Applied Sciences, Engineering and Technology, 5(10): 3010-3014.

[8] FERnÁNDEZ MNP. 2017. Fuzzy theory and quality control charts. In: IEEE International Conference on Fuzzy Systems. pp. 1-6. 
[9] GÜlbay M, Kahraman C \& RuAn D. 2004. $\alpha$-cut fuzzy control charts for linguistic data. International Journal of Intelligent Systems, 19(12): 1173-1195.

[10] Kahraman C, Gülbay M \& Boltürk E. 2016. Fuzzy Shewhart Control Charts. Fuzzy Statistical Decision-Making, 343(1): 263-280.

[11] Kaya I, ERdoĞAn M \& Yildiz C. 2017. Analysis and control of variability by using fuzzy individual control charts. Applied Soft Computing, 51: 370-381.

[12] Machado MAG \& Costa AFB. 2014. Some comments regarding the synthetic $\bar{X}$ chart. Communications in Statistics - Theory and Methods, 43(14): 2897-2906.

[13] MAsood I \& Shyen VBE. 2016. Quality control in hard disc drive manufacturing using pattern recognition technique. IOP Conference Series: Materials Science and Engineering, 160: 1-7.

[14] MOnTGOMERY DC. 2009. Introduction to statistical quality control. Jefferson City: John Wiley \& Sons.

[15] Moraditadi A \& Avakhdarestani S. 2016. Development of fuzzy individual x and moving range control chart. International Journal of Productivity and Quality Management, 17(1): 82-103.

[16] OU Y, WEN D, WU Z \& KHOо MBC. 2011. A comparison study on effectiveness and robustness of control charts for monitoring process mean and variance. Quality and Reliability Engineering International, 28(1): 3-17.

[17] Senturk S \& Antucheviciene J. 2017. Interval type-2 fuzzy c-control charts: An application in a food company. Informatica, 28(2): 269-283.

[18] Senturk S \& Erginel N. 2009. Development of fuzzy $\bar{X}-R$ and $\bar{X}-S$ control charts using $\alpha$-cuts. Information Sciences, 179(10): 1542-1551.

[19] WANG JH \& RAZ T. 1990. On the construction of control charts using linguistic variables. The International Journal of Production Research, 28(3): 477-487.

[20] Wu Z, YAng M, Jiang W \& Khoo MBC. 2008. Optimization designs of the combined Shewhart-CUSUM control charts. Computational Statistics \& Data Analysis, 53(2): 496506.

[21] ZADEH LA. 1965. Fuzzy sets. Information and control, 8(3): 338-353. 